\title{
The Association Between Tobacco Control Policy and Educational Inequalities in Smoking Cessation in the Netherlands from 1988 Through 2011
}

Citation for published version (APA):

Bosdriesz, J. R., Nagelhout, G. E., Stronks, K., Willemsen, M. C., \& Kunst, A. E. (2015). The Association Between Tobacco Control Policy and Educational Inequalities in Smoking Cessation in the Netherlands from 1988 Through 2011. Nicotine \& Tobacco Research, 17(11), 1369-1376.

https://doi.org/10.1093/ntr/ntv004

Document status and date:

Published: 12/01/2015

DOI:

10.1093/ntr/ntv004

Document Version:

Publisher's PDF, also known as Version of record

Document license:

Taverne

Please check the document version of this publication:

- A submitted manuscript is the version of the article upon submission and before peer-review. There can be important differences between the submitted version and the official published version of record.

People interested in the research are advised to contact the author for the final version of the publication, or visit the DOI to the publisher's website.

- The final author version and the galley proof are versions of the publication after peer review.

- The final published version features the final layout of the paper including the volume, issue and page numbers.

Link to publication

\footnotetext{
General rights rights.

- You may freely distribute the URL identifying the publication in the public portal. please follow below link for the End User Agreement:

www.umlib.nl/taverne-license

Take down policy

If you believe that this document breaches copyright please contact us at:

repository@maastrichtuniversity.nl

providing details and we will investigate your claim.
}

Copyright and moral rights for the publications made accessible in the public portal are retained by the authors and/or other copyright owners and it is a condition of accessing publications that users recognise and abide by the legal requirements associated with these

- Users may download and print one copy of any publication from the public portal for the purpose of private study or research.

- You may not further distribute the material or use it for any profit-making activity or commercial gain

If the publication is distributed under the terms of Article 25fa of the Dutch Copyright Act, indicated by the "Taverne" license above, 


\title{
The Association Between Tobacco Control Policy and Educational Inequalities in Smoking Cessation in the Netherlands from 1988 Through 2011
}

\author{
Jizzo R. Bosdriesz MSc ${ }^{1}$, Gera E. Nagelhout PhD ${ }^{2,3}$, Karien Stronks PhD', \\ Marc C. Willemsen PhD ${ }^{2,3}$, Anton E. Kunst PhD' \\ 'Department of Public Health, Academic Medical Center, University of Amsterdam, Amsterdam, The Netherlands; \\ ${ }^{2}$ Department of Health Promotion, Maastricht University (CAPHRI), Maastricht, The Netherlands; ${ }^{3}$ Alliance Smokefree \\ Holland, The Hague, The Netherlands
}

Corresponding Author: Jizzo R. Bosdriesz, MSc, Department of Public Health P0 Box 22660, 1100 DD Amsterdam, The Netherlands. Telephone: +31-20-5661526; Fax: +31-20-6972316; E-mail: j.bosdriesz@amc.uva.nl

Received April 28, 2014; accepted December 29, 2014

\begin{abstract}
Introduction:Tobacco control policies seemed to have failed to reduce socioeconomic inequalities in smoking in the past. It has been argued that a comprehensive mix of policies is needed. Our aim was to assess whether tobacco control policy development in the Netherlands between 1988 and 2011 was associated with educational inequalities in smoking cessation and cigarette consumption. Methods: Data were derived from the cross-sectional Dutch Continuous Survey of Smoking Habits, with a study sample of 259,140 respondents from 1988 through 2011. Outcomes were the quit ratio and mean number of cigarettes smoked per day. The determinant was the Tobacco Control Scale (TCS). We used multilevel logistic regression modeling, with years, quarters, and individuals as levels, and controlled for sex, age, and time.

Results: A significant association between theTCS and smoking cessation was found in 2001-2011, but not in 1988-2000. Associations for low- and high-education groups were similar $(O R=1.23$; $95 \% \mathrm{Cl}=1.12-1.34$ and $O R=1.17 ; 95 \% \mathrm{Cl}=1.03-1.32$ respectively). The TCS was not significantly associated with the number of cigarettes smoked per day for either the low- or high-education groups ( $B=-0.09 ; 95 \% \mathrm{Cl}=-0.46-0.27$ and $B=-0.59 ; 95 \% \mathrm{Cl}=-1.24-0.06$ respectively).

Conclusions: Strong tobacco control policies introduced in the Netherlands after 2000 were positively associated with national trends in smoking cessation, whereas weaker policies introduced gradually before 2000 were not. However, these measures do not seem to have either widened or narrowed educational inequalities in smoking cessation rates-both groups benefitted about equally.
\end{abstract}

\section{Introduction}

Smoking is the most important preventable cause of disease and premature death worldwide. ${ }^{1}$ Moreover, smoking is the largest contributor to socioeconomic inequalities in mortality, responsible for roughly half of the difference in adult male mortality between high- and low-socioeconomic status (SES) groups. ${ }^{2}$ Many tobacco control policies have been implemented to reduce the prevalence of smoking and the resulting morbidity and mortality, especially since the World Health Organization (WHO) introduced the Framework Convention on Tobacco Control (FCTC) in May 2003. ${ }^{3}$ 
Previous research has shown that many FCTC policies have been effective in reducing smoking prevalence in the general population, but have largely failed to decrease inequalities. ${ }^{4,5}$ In many European countries, including the Netherlands, inequalities have actually become greater. ${ }^{6,7}$ However, it is unknown whether this has been the result of tobacco control policies or whether this reflects a secular trend over a longer period of time. To be effective in decreasing socioeconomic inequalities in smoking, several policies, effective among low-SES groups, need to be combined. ${ }^{4}$ This resembles the approach included in a WHO handbook to help implement policies based on the FCTC: "For tobacco control to succeed, a comprehensive mix of policies and strategies is needed." 8

In the Netherlands, the introduction of new tobacco control policy measures can be divided into two distinct phases. The first phase was characterized by the introduction of minor measures in 1990, such as a smoking ban in government buildings only, an advertising ban on television only, and slight tax increases, followed by almost 10 years with no significant new measures. Starting at the beginning of the 21st century, bans on smoking in all workplaces and hospitality venues were introduced in quick succession, combined with several tax increases and large-scale public information campaigns. All of these measures are regarded as effective ways of reducing the prevalence of smoking. ${ }^{9-12}$

Our study aimed to assess whether developments in tobacco control policy in the Netherlands were associated with smoking cessation and smoking intensity. One of the benefits of using the Dutch Continuous Survey of Smoking Habits is that it contains continuous data over a period of 24 years.

Our specific research aims were:

- To study the associations between developments in tobacco control policy in the Netherlands during 1988-2000 and 2001-2011 and changes in the quit ratio.

- For the second period (2001-2011), we also studied the associations with smoking intensity among current smokers.

- To assess whether any of the associations we found were different for low- and high-education groups.

\section{Methods}

\section{Population}

We used data from a repeated cross-sectional national population survey, the Dutch Continuous Survey of Smoking Habits (DCSSH). The DCSSH was conducted for STIVORO, the Dutch Expert Centre on Tobacco Control, by the research firm TNS NIPO. Each year, approximately 19,000 respondents aged 15 years and above were surveyed in a stratified random sample. Household face-to-face interviewing was used from 1988 through 2000; household computer-assisted web interviewing was used from 2001 through 2008. And from 2009, a personal-level individual web survey was used. Response rates were not available for each year, but for 2011, the response rate was $69.6 \%$.

We aimed to study two separate periods, to compare a period of weak tobacco control policy with a period with stronger tobacco control policy. The boundary between these two phases would be somewhere between 2000 and 2002. We have chosen 2001 as the start of the second period, because this coincides with the change from face-to-face interviewing to computer-assisted web interviewing. This methodological change resulted in a significant change in the pattern of both the quit ratio and some of the covariates (listed below). The 2009 change to individual-level surveying resulted in only negligible changes in these patterns, and therefore 2001-2011 was analyzed as one period.

From an initial dataset of 471,568 respondents, 67 were excluded because of missing data on their smoking status. Next, we excluded 209,971 never-smokers because we were only interested in smoking cessation among those who had ever smoked. An additional 2,390 respondents $(0.9 \%)$ were excluded because of missing data on their education level. This resulted in a final sample of 259,140 respondents, whose characteristics are shown in Table 1. For the analyses on intensity of smoking, there were 47,179 smokers with valid data.

We have written confirmation from the Medical Ethics Review Committee of the Academic Medical Center that the Dutch Medical Research Involving Human Subjects Act (WMO) (based on the principles of the Declaration of Helsinki) does not apply to this study. Because study participants were not subjected to treatment or required to perform any behavior, no official approval was required.

\section{Variables}

Our outcome variables were the odds of quitting smoking, represented by the quit ratio, which is the proportion of former smokers to "ever-smokers" (current smokers plus former smokers) and the mean number of cigarettes smoked per day, per current smoker. The latter variable could only be analyzed for 2001-2011, as this variable was not included as a continuous variable in the DCSSH before 2001 .

Our main determinant was the total Tobacco Control Scale (TCS), a scale first developed in 2005 by Joossens and Raw to monitor and compare tobacco control polices. ${ }^{13}$ The TCS combines data on six domains of tobacco control policy, these are listed in Box 1. We calculated the TCS scores based on the original methodology, for each time period for which DCSSH data were available. The data for domains 2, 4, 5, and 6 (Box 1) were derived from the report of the Pricing Policies and Control of Tobacco in Europe Project, ${ }^{14}$ and the Dutch Tobacco Act; ${ }^{15}$ data on tobacco prices were obtained from the Tobacco Manufacturers' Association (P Stockall, personal communication, 2012), and data on public information campaigns were obtained from STIVORO by one of the authors (M Willemsen, personal communication, 2012). The detailed TCS scores can be found in Supplementary Table 1.

SES was measured using the education level of the main breadwinner. This was dichotomized into: low (primary education/lower secondary education) and high (upper secondary education/tertiary education). Educational level (in the Netherlands) is usually measured in three or four categories. We did this in a sensitivity analysis, but as this did not lead to different conclusions, we continued with the two categories. Other variables included in the analyses

\section{Box 1 Domains of the Tobacco Control Scale}

1. Price increases through higher taxes on tobacco products.

2. Bans/restrictions on smoking in public places and workplaces.

3. Public information campaigns.

4. Comprehensive bans on advertising and promotion of tobacco products.

5. Large, direct health warning labels on cigarette packages.

6. Treatment to help dependent smokers stop, including medication. 
as covariates were sex (male/female) and age (categories: 15-34, $35-54,55$ and older).

\section{Analysis}

Multilevel logistic regression modeling was used to analyze the association between the TCS and the quit ratio. We have chosen to use multilevel modeling, which allows for clustering of respondents. We did assume that respondents interviewed within one period may represent dependent observations, as they share a common context. We have clustered respondents by interview period, with individuals being the first level, quarters the second level, and years the third level. All analyses were performed separately for two periods: 1988 through 2000 and 2001 through 2011.

We controlled for age, sex, and calendar time, to control for confounding by other processes that occur over time. In addition, we tested, for all outcomes and all periods separately, whether the TCS had a statistically significant interaction with, respectively, age, sex, and education. For each interaction separately, we added the corresponding interaction term to the model that only included zero-order variables. As we found significant interaction with both education and age but not with sex, we have stratified the analysis according to education and age.

Outcomes are presented as odds ratios (ORs) and 95\% CIs, which indicate the odds of quitting smoking associated with a 10 -point increase on the TCS, because for the analyses, all TCS scores were divided by 10 . This was done to present outcomes associated with an increase in policy that can be expected to have an impact on smoking cessation, for example, implementing pictorial warnings will add 4 points and implementing fully smoke-free bars and restaurants will add 8 points.

The association between the TCS and number of cigarettes smoked was studied in a multilevel linear regression model similar in design to the logistic model described above. Outcomes are presented as betas, which indicate smoking one additional cigarette per day, associated with a 10-point increase on the TCS.

There is likely to be a delay between developments in tobacco control policy and their possible effect on smoking cessation. For instance, the effect of tax increases may be gradual, ${ }^{16-18}$ while smokefree legislation can have an effect from the day it is introduced, or even beforehand. ${ }^{19}$ To analyze lag-times, we allocated to all respondents the TCS scores of 1, 2, and 3 years before the year they were interviewed. After this first analysis, the lag-time variable that showed the strongest association with the quit ratio was used in further analyses.

All analyses were performed in $\mathrm{R}$ (version 2.15.2). With the current statistical packages, we were not able to perform a multilevel analysis that takes survey weights into account. Not all variables included in the survey weights could be adjusted for (province, community size, family size). Control for these variables would probably not substantially influence our trend analysis, as the association of these variables with smoking, if any, does not appear to strongly change over time. ${ }^{20}$ We did perform a weighted "flat" regression, as a sensitivity analysis, which provided results similar to those from the multilevel analysis.

\section{Results}

Table 1 shows that quit ratios are roughly equal for men and women, but on average higher for the high-education group than for the loweducation group. With increasing age, former smokers make up an increasingly large proportion of ever smokers (current smokers plus former smokers), especially so in 2001-2011.

Figure 1 shows the development of the TCS in the Netherlands, with significant measures introduced highlighted in the figure legend. Before 2001, increases were slow and subtle, after one marked increase in 1990. More rapid developments followed in the later period, with two marked increases in 2003 and 2008. The quit ratio
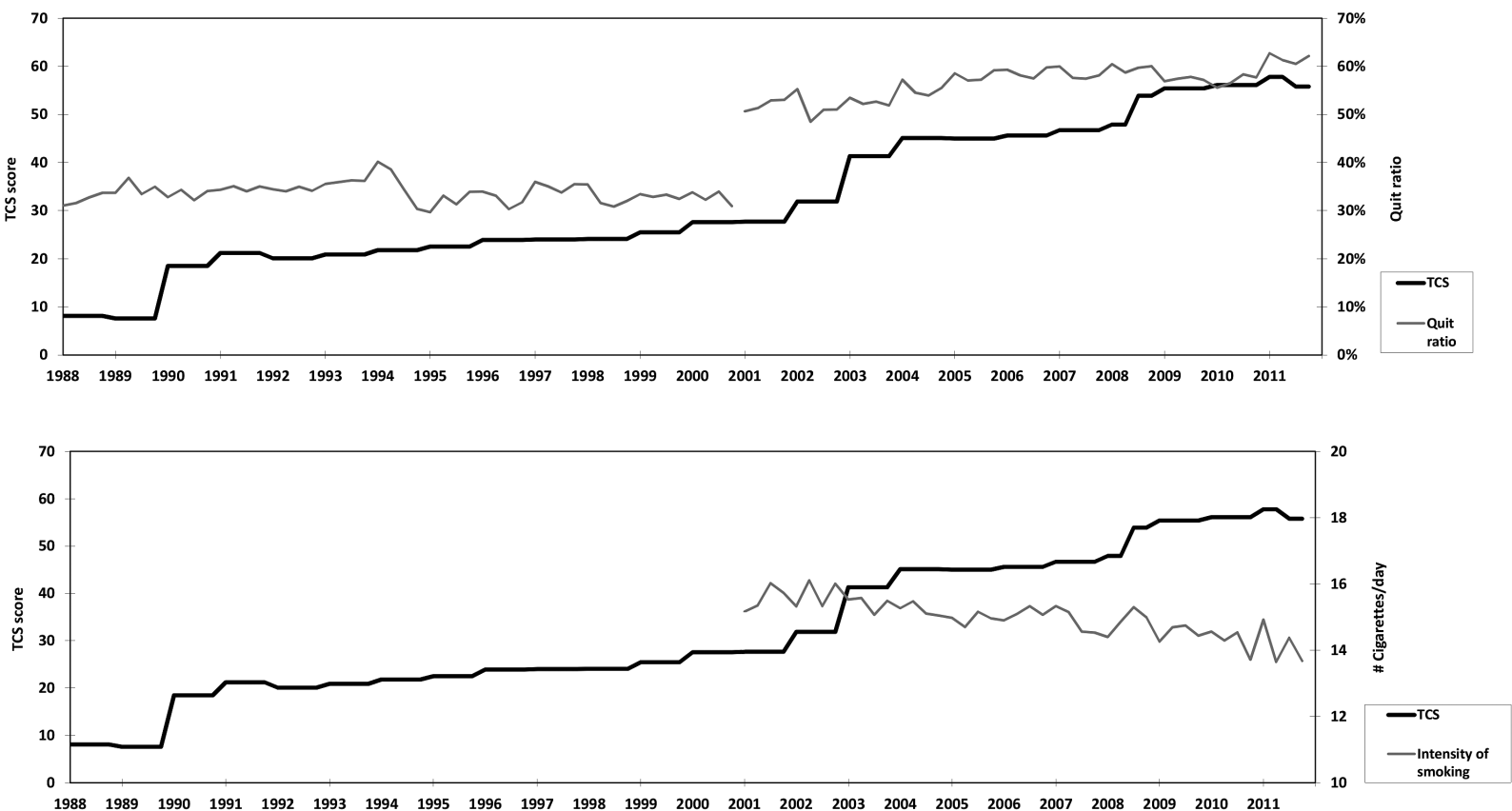

Figure 1. The Tobacco Control Scale scores with quit ratios from 1988-2011 and the intensity of smoking from 2001-2011. 1990 = introduction of smoking ban in government buildings; ban on TV advertising; mandatory health text warnings on tobacco products. $2003=$ introduction of smoking ban in workplaces; bans on outdoor, print media, indirect and internet advertising and sponsorship. $2008=$ introduction of smoking ban in cafes and restaurants, tax increase and mass media campaign. Note: Due to a change in methodology, the periods of 1988-2000 and 2001-2011 were separated. Data on intensity of smoking were only available for 2001-2011. 
remained quite stable over the period 1988-2000, while over the period 2001-2011 an increase was apparent. Due to the change in survey methods, the absolute levels of the quit ratio for these two periods should not be compared. During the second period, the mean number of cigarettes smoked per day showed a gradual decline (Figure 1).

Table 2 shows the associations between the TCS and the quit ratio. For the general population, all associations for 1988-2000 were negative and nonsignificant. However, for 2001-2011, all associations with 1- and 2-year lag times were positive and significant.
An increase of 10 points on the TCS scale was associated with an increase of $20 \%$ in the quit ratio $(O R=1.20$, with a 2 -year lag). We found significant interaction between the TCS and education, except in 1988-2000. When stratified by education, we found associations between the TCS and the quit ratio to be similar for the low- and high-education groups. Although for the high-education group, this association was strongest after a 1 -year lag $(O R=1.24)$, while for the low-education group this was strongest after a 2 -year lag $(O R=1.23)$.

Table 1. Sample Size and Quit Ratios of the Study Population by Education and Age

\begin{tabular}{|c|c|c|c|c|c|c|}
\hline & \multicolumn{3}{|c|}{ 1988-2000 } & \multicolumn{3}{|c|}{ 2001-2011 } \\
\hline & \multicolumn{3}{|c|}{ Education $^{\mathrm{a}}$} & \multicolumn{3}{|c|}{ Education $^{\mathrm{a}}$} \\
\hline & Total & Low & High & Total & Low & High \\
\hline \multicolumn{7}{|l|}{$N$} \\
\hline Age $15-34$ & 43,844 & 30,849 & 12,995 & 24,525 & 15,208 & 9,317 \\
\hline Age $35-54$ & 58,842 & 40,991 & 17,851 & 50,274 & 35,333 & 14,941 \\
\hline Age $\geq 55$ & 31,909 & 24,959 & 6,950 & 49,746 & 32,662 & 17,084 \\
\hline Total & 134,595 & 96,799 & 37,796 & 124,545 & 83,203 & 41,342 \\
\hline \multicolumn{7}{|l|}{ Quit ratio $^{b}$} \\
\hline Age $15-34$ & 20.2 & 18.3 & 24.7 & 32.8 & 30.2 & 36.9 \\
\hline Age $35-54$ & 34.4 & 31.8 & 40.5 & 49.6 & 47.6 & 54.3 \\
\hline Age $\geq 75$ & 48.9 & 47.3 & 54.6 & 74.1 & 72.5 & 77.1 \\
\hline Total & 33.2 & 31.5 & 37.7 & 56.1 & 54.2 & 59.8 \\
\hline
\end{tabular}

PRESS RELEASE ${ }^{a}$ Education: low = primary education/lower secondary education; high = higher secondary education/tertiary education.

${ }^{\mathrm{b}} \mathrm{Q}$ uit ratio $=$ former smokers / (current smokers + former smokers).

Table 2. Associations Between the Tobacco Control Scale (TCS) With Different LagTimes and Both Smoking Cessation and Smoking Intensity, Stratified by Education

\begin{tabular}{|c|c|c|c|c|c|c|c|}
\hline & \multicolumn{2}{|c|}{ Total population } & \multicolumn{2}{|c|}{ Low education ${ }^{a}$} & \multicolumn{2}{|c|}{ High education $^{\mathrm{b}}$} & \multirow[b]{2}{*}{$p$ value $^{\mathrm{d}}$} \\
\hline & $O R / B^{c}$ & $95 \% \mathrm{CI}$ & $O R / B^{c}$ & $95 \% \mathrm{CI}$ & $O R / B^{c}$ & $95 \% \mathrm{CI}$ & \\
\hline \multicolumn{8}{|c|}{ Outcome: smoking cessation } \\
\hline \multicolumn{8}{|c|}{ 1988-2000 } \\
\hline TCS 3 years before & 0.93 & $0.87-1.00$ & 0.93 & $0.86-1.01$ & 0.95 & $0.88-1.02$ & .231 \\
\hline TCS 2 years before & 0.94 & $0.88-1.01$ & 0.95 & $0.88-1.02$ & 0.94 & $0.88-1.00$ & .253 \\
\hline TCS 1 year before & 0.94 & $0.88-1.00$ & 0.94 & $0.88-1.00$ & 0.93 & $0.87-1.00$ & .388 \\
\hline TCS current year & 0.95 & $0.89-1.01$ & 0.95 & $0.89-1.02$ & 0.94 & $0.88-1.00$ & .652 \\
\hline \multicolumn{8}{|l|}{ 2001-2011 } \\
\hline TCS 3 years before & 1.03 & $0.93-1.14$ & 1.08 & $0.96-1.22$ & 0.95 & $0.82-1.10$ & .050 \\
\hline TCS 2 years before & 1.20 & $1.10-1.30$ & 1.23 & $1.12-1.34$ & 1.17 & $1.03-1.32$ & .016 \\
\hline TCS 1 year before & 1.15 & $1.05-1.26$ & 1.14 & $1.02-1.27$ & 1.24 & $1.12-1.37$ & .002 \\
\hline TCS current year & 1.04 & $0.95-1.15$ & 1.00 & $0.90-1.12$ & 1.13 & $0.99-1.28$ & $<.001$ \\
\hline \multicolumn{8}{|c|}{ Outcome: smoking intensity } \\
\hline \multicolumn{8}{|c|}{$2001-2011^{\mathrm{e}}$} \\
\hline TCS 3 years before & -0.09 & $-0.47-0.29$ & -0.02 & $-0.41-0.37$ & -0.25 & $-0.90-0.41$ & .013 \\
\hline TCS 2 years before & -0.22 & $-0.58-0.14$ & -0.06 & $-0.43-0.31$ & -0.58 & $-1.17-0.00$ & .007 \\
\hline TCS 1 year before & -0.20 & $-0.55-0.15$ & -0.05 & $-0.41-0.31$ & -0.62 & $-1.19-0.05$ & .006 \\
\hline TCS current year & -0.00 & $-0.34-0.34$ & 0.08 & $-0.26-0.42$ & -0.24 & $-0.81-0.33$ & .011 \\
\hline
\end{tabular}

$\mathrm{CI}=$ confidence interval. All models were adjusted for age, sex, and time (coefficients for time were: for 1988-2000, 0.76 (0.64-0.91) for low education and 0.80 (0.65-0.99) for high education; for 2001-2011, 0.88 (0.83-0.95) for low education and 0.94 (0.85-1.03) for high education). Significant associations and significant interactions $(p<.05)$ are highlighted in bold.

${ }^{a}$ Low education: primary education/lower secondary education.

bHigh education: higher secondary education/tertiary education.

'The coefficients for the smoking cessation models are odds ratios, the coefficients for the smoking intensity models are beta's.

dThe $p$ value for interaction between TCS and education (reference: low).

${ }^{\mathrm{e}}$ The number of cigarettes smoked per day was not included in the questionnaire before 2001 . 
Table 2 also shows the association between the TCS and the number of cigarettes smoked. A negative trend is apparent, indicating that developments in tobacco control policy would result in a drop in the number of cigarettes smoked per day by current smokers. Interaction between the TCS and education was significant, with stronger associations for the high-education group than for the low-education group. However, only one of the presented associations-for high-educated smokers with a 1-year lag-was statistically significant.

Interaction between sex and the TCS was not significant, while interaction between age and the TCS was significant for the low education group. Table 3 shows the associations between the TCS and the quit ratio, stratified by both education and age. For 2001-2011 the association between the TCS and the quit ratio was strongest for the youngest group (15-34 years) and decreased in strength with increasing age. For all age groups, the effect among the low education group was stronger, which follows the main results with a 2-year lag time.

Table 3 also shows that for smoking intensity among both education groups, there is significant interaction between the TCS and age. The association between TCS and smoking intensity was somewhat stronger for the older high-education groups and the younger loweducation groups, but none were significant.

\section{Discussion}

We found that developments in tobacco control policy in the Netherlands were significantly associated with an increase in the number of people who quit smoking between 2001 and 2011, but not between 1988 and 2000. Developments in tobacco control policy were not significantly associated with smoking intensity among current smokers. For both outcomes, the strength of the associations was similar for low- and high-education groups. Furthermore, our results suggest that there might be a difference in timing in the association of tobacco control policy with smoking cessation between the low- and high-education groups.

\section{Limitations}

The quit ratio is a cumulative measure, containing information about the proportion of people who have successfully quit smoking, which has been used in several other studies. ${ }^{21,22}$ Because it does not contain information on when people quit smoking, the quit ratio may not be very responsive to short-term changes. As a result, the associations between tobacco control policy and smoking cessation may be underestimated. However, the quit ratio is relative stable; by including less recent quitters it may be less sensitive to temporary quitters who will relapse after a few months or years. Therefore, despite its limitations, the quit ratio may be useful to detect effects that develop over longer lag-times. For assessing direct effects of tobacco control policies, more detailed smoking cessation data would be required.

Societal attitudes towards smoking have changed considerably over the 20-year period this study covers, which could have affected our results. One possibility is that the social desirability bias, increased when smoking became less accepted. However, one of the very few studies on this effect found no difference in social desirability bias between youths who were or were not exposed to the "Truth campaign." 23

Because our aim was to study combined policies, the many tobacco control policies implemented during the study period were analyzed as a whole. Data on the six separate domains (Box 1) are available, but statistical models proved too unstable to perform multivariate analyses on separate domains due to insufficient variation in the policy domains.

Table 3. Associations Between the Tobacco Control Scale (TCS) and Smoking Cessation for Men and Women and Different Age Groups With a 2-Year Lag Time, Stratified by Education

\begin{tabular}{|c|c|c|c|c|c|c|}
\hline \multirow[b]{2}{*}{ TCS coefficient } & \multicolumn{2}{|c|}{ Low education ${ }^{a}$} & \multirow[b]{2}{*}{$p$ value $^{\mathrm{d}}$} & \multicolumn{2}{|c|}{ High education $^{\mathrm{b}}$} & \multirow[b]{2}{*}{$p$ value $^{\mathrm{d}}$} \\
\hline & $O R / B^{c}$ & $95 \% \mathrm{CI}$ & & $O R / B^{c}$ & $95 \% \mathrm{CI}$ & \\
\hline \multicolumn{7}{|c|}{ Outcome: smoking cessation } \\
\hline \multicolumn{7}{|c|}{ 1988-2000 } \\
\hline Age 15-34 & 0.99 & $0.97-1.01$ & ref & 1.01 & $0.99-1.03$ & ref \\
\hline Age $35-54$ & 0.98 & $0.97-1.01$ & .308 & 0.99 & $0.98-1.01$ & .843 \\
\hline Age $\geq 55$ & 1.00 & $0.99-1.01$ & .217 & 0.98 & $0.97-1.05$ & .281 \\
\hline \multicolumn{7}{|l|}{ 2001-2011 } \\
\hline Age 15-34 & 1.43 & $1.09-1.87$ & ref & 1.20 & $0.89-1.60$ & ref \\
\hline Age $35-54$ & 1.19 & $1.08-1.30$ & .004 & 1.14 & $1.00-1.31$ & .718 \\
\hline Age $\geq 55$ & 1.18 & $1.07-1.31$ & .019 & 1.12 & $0.96-1.31$ & .704 \\
\hline \multicolumn{7}{|c|}{ Outcome: smoking intensity } \\
\hline \multicolumn{7}{|c|}{$2001-2011^{\mathrm{e}}$} \\
\hline Age $15-34$ & 0.02 & $-1.01-1.05$ & ref & 0.28 & $-1.15-1.70$ & ref \\
\hline Age $35-54$ & 0.14 & $-0.52-0.80$ & .010 & -0.79 & $-2.19-0.61$ & $<.001$ \\
\hline Age $\geq 55$ & -0.05 & $-0.99-0.89$ & .091 & -0.41 & $-2.23-1.42$ & $<.001$ \\
\hline
\end{tabular}

$\mathrm{CI}=$ confidence interval. Sex-stratified models were adjusted for age and time, Age-stratified models were adjusted for sex and time. Significant associations and significant interactions $(p<.05)$ are highlighted in bold.

a Low education: primary education/lower secondary education.

'High education: higher secondary education/tertiary education.

'The coefficients for the smoking cessation models are odds ratios, the coefficients for the smoking intensity models are beta's.

'The $p$ value for interaction between TCS and education (reference: age 15-34).

'The number of cigarettes smoked per day was not included in the questionnaire before 2001. 


\section{Interpretation of Results}

The impact of combined tobacco control policies on smoking cessation has not been studied extensively. The only study we found was a comparison of 18 European countries, which showed that a higher TCS score was associated with a higher quit ratio, with no significant differences between SES groups. ${ }^{24}$ We did find more studies that looked at the effects of combined policies on smoking prevalence, rather than smoking cessation. These reported mixed results: one found no significant effect, ${ }^{25}$ and another found a strong decrease. ${ }^{26}$ Yet other studies provided a more nuanced view: one study found that tax increases and media campaigns were most effective in promoting smoking cessation, ${ }^{27}$ and another study suggested that a smoke-free hospitality industry law had the strongest impact on smoking cessation, whereas the effect of the small price increase in the same year was only observed among younger smokers. ${ }^{28} \mathrm{~A}$ review study suggested that countries where several tobacco control policy measures had been combined experienced a greater decline in smoking among low-SES groups than other countries. ${ }^{29}$

In order to provide more insight into the mechanisms behind the found associations, one needs to look at the specific policy measures contained in the TCS. However, unraveling the contribution of specific policies to a decline in smoking is quite difficult when several policies are introduced simultaneously. ${ }^{30}$ We can only speculate on which measures have contributed most by comparing their development between the two periods and looking at evidence from international literature. Taxes on tobacco products remained fairly stable in the Netherlands during the 1990s, but almost doubled between 2001 and 2011. Because large tax increases are considered to be the most effective strategy for reducing smoking rates, especially among low-SES groups, ${ }^{9}$ increased taxation may have played a major role.

Smoking was banned in workplaces in 2004 and in hospitality venues in 2008 (with exceptions). Because strong smoke-free laws have been shown to be effective in increasing smoking cessation, ${ }^{11,12}$ we assume that they also contributed to the associations between policies and quitting. However, this association might be mitigated by the large amount of negative attention and resistance to this measure that was seen in national media. It has been shown that this can lead to less support for smoke-free laws. ${ }^{31}$

Expenditures on public information campaigns peaked around 2003-2004, and afterwards declined to the lower level of the 1990s. As public information campaigns may be effective, especially when combined with other measures, ${ }^{10}$ they might have played a moderate role.

The effects of the other domains are generally regarded as weaker, ${ }^{32,33}$ and because developments in the Netherlands in these domains were stronger in the first period or equal in both periods, they cannot explain the difference in the associations found between the two periods.

A key difference between the two periods is the time between implementation of new measures. By implementing new measures in rapid succession, the "comprehensive mix of policies and strategies" called for by the WHO may have been achieved in the second period. ${ }^{8}$

Another study that used the DCSSH found that between 2001 and 2008, educational inequalities in smoking cessation had increased, particularly among women. ${ }^{6}$ In seeming contrast to this, we found no differential association between tobacco control policy and the quit ratios among low- and high-education groups. Our results provide indications to suggest that the increase in inequalities in smoking cessation observed earlier was not the (unintended) effect of the studied tobacco control policies. Other factors that could be responsible for the increase in inequalities include the social context, which can mitigate the effects of policies on individual behaviour. ${ }^{34}$

The strongest associations between the TCS and the quit ratio were seen for the youngest age groups, both in the low- and higheducation groups. Because young adults quit smoking relatively recently, quit ratios are more likely to have been influenced by recent policy measures. Other studies have found that smoking cessation in young adults is especially responsive to tax/price increases. ${ }^{5,28}$

For the low-education group, the strongest association between tobacco control policies and smoking cessation was found 2 years after policy implementation, compared with 1 year for the higheducation group. To our knowledge, our study is the first to suggest differences between education groups in the timing of tobacco control policies' effect on smoking cessation. One possible mechanism could be that the smoking behavior of people in lower socioeconomic groups is more strongly mediated by social networks..$^{34,35}$ Moreover, a change in social norms is likely to occur first in the higheducation groups, ${ }^{36}$ before it can trickle down to the low-education groups. Finally, quit success is lower among low-education groups. ${ }^{37}$ Therefore, it may take more quit attempts-and thus more time-for the low-education group to be as successful in quitting as the higheducation group. ${ }^{38}$

Among current smokers, we found a modest association between the TCS and number of cigarettes smoked per day, only significant among the high education group. This can be related to the hardening hypothesis (as smoking becomes less prevalent, the proportion of smokers not wanting to quit or not able to quit is likely to increase). ${ }^{39}$ Because our data shows no effect for the low education group, it could be argued that the low education group is "hardening."

\section{Conclusions}

In line with the recommendation made by the WHO, our results suggest that a "comprehensive mix of policies" can have a significant positive effect on smoking cessation. The experience of the Netherlands in the 1990s illustrates that weaker and more gradual increases are not likely to have a meaningful impact on quit ratios. Even though a comprehensive mix of policies was introduced after 2001, we found no decrease in educational inequalities in smoking cessation. However, despite fears that many tobacco control policies are effective mainly in high-SES groups, the studied policies did not increase educational inequalities either. Therefore, we conclude that the comprehensive mix of tobacco control policies implemented in the Netherlands between 2001 and 2011 had an equally positive association with quit ratios for low- and high-socioeconomic groups.

\section{Supplementary Material}

Supplementary Tables 1 and 2 can be found online at http://www. ntr.oxfordjournals.org

\section{Funding}

This study is part of the project "Tackling socioeconomic inequalities in smoking (SILNE)," which is funded by the European Commission, DirectorateGeneral for Research and Innovation, under the FP7-Health-2011 program, with grant agreement number 278273. The Dutch Continuous Survey of 
Smoking Habits (DCSSH) was supported by grants from the Dutch Ministry of Health, Welfare, and Sport.

\section{Declaration of Interests}

None declared.

\section{Acknowledgments}

The authors wish to thank W. Busschers for advice on and assistance with statistical analyses. Furthermore, the authors wish to thank all participants of the SILNE project for feedback on an early draft of the paper. JRB and AEK conceived and designed the study. GEN prepared the data. JRB conducted the statistical analyses, interpreted the data and drafted the manuscript. He is the guarantor of the paper. GEN, KS, MCW, and AEK contributed to the interpretation of the data and critically revised the manuscript for important intellectual content. All authors have read and approved the final manuscript.

\section{References}

1. Word Health Organization. Mortality attributable of tobaco: WHO Global Report. WHO Libr Cat Data. 2012:4. http://www.who.int/tobacco/publications/surveillance/rep_mortality_attributable/en/. Accessed December 30, 2014.

2. Jha P, Peto R, Zatonski W, Boreham J, Jarvis MJ, Lopez AD. Social inequalities in male mortality, and in male mortality from smoking: indirect estimation from national death rates in England and Wales, Poland, and North America. Lancet. 2006;368:367-370.

3. Word Health Organization. World Health Organisation Framework Convention on Tobacco Control. 2012. http://www.who int/fctc/en/. Accessed December 30, 2014

4. Hiscock R, Bauld L, Amos A, Fidler JA, Munafò M. Socioeconomic status and smoking: a review. Ann N Y Acad Sci. 2012;1248:107-123.

5. Thomas S, Fayter D, Misso K, et al. Population tobacco control interventions and their effects on social inequalities in smoking: systematic review. Tob Control. 2008;17:230-237.

6. Nagelhout GE, de Korte-de Boer D, Kunst AE, et al. Trends in socioeconomic inequalities in smoking prevalence, consumption, initiation, and cessation between 2001 and 2008 in the Netherlands. Findings from a national population survey. BMC Public Health. 2012;12:303.

7. Giskes K, Kunst AE, Benach J, et al. Trends in smoking behaviour between 1985 and 2000 in nine European countries by education. J Epidemiol Community Health. 2005;59:395-401.

8. WHO Tobacco Free Initiative. Building blocks for tobacco control: a handbook. Addiction. 2005;100:1563-1564.

9. Chaloupka FJ, Yurekli A, Fong GT. Tobacco taxes as a tobacco control strategy. Tob Control. 2012;21:172-180.

10. Durkin S, Brennan E, Wakefield M. Mass media campaigns to promote smoking cessation among adults: an integrative review. Tob Control. 2012;21:127-138.

11. Fichtenberg CM, Glantz SA. Effect of smoke-free workplaces on smoking behaviour: systematic review. BMJ. 2002;325:188.

12. Hopkins DP, Razi S, Leeks KD, Priya Kalra G, Chattopadhyay SK, Soler RE. Smokefree policies to reduce tobacco use. A systematic review. Am J Prev Med. 2010;38: S275-S289. doi:10.1016/j.amepre.2009.10.029.

13. Joossens L, Raw M. The Tobacco Control Scale: a new scale to measure country activity. Tob Control. 2006;15:247-253.

14. Nguyen L, Rosenqvist G, Pekurinen M. Demand for Tobacco in Europe. An Econometric Analysis of 11 Countries for the PPACTE Project. Tampere, Finland: Juvenes Print-Tampereen yliopistopaino Oy; 2012:121-131. http://www.thl.fi/documents/605763/1449622/ Demandfortobaccoineurope.pdf/229571d8-313b-4eea-bd 9a617a1309681e. Accessed December 30, 2014.
15. Dutch Tobacco Law [Tabakswet]. BWBR0004302. 1988. http://wetten. overheid.nl/BWBR0004302/geldigheidsdatum_30-12-2014. Accessed December 30, 2014.

16. Chaloupka FJ, Cummings KM, Morley CP, Horan JK. Tax, price and cigarette smoking: evidence from the tobacco documents and implications for tobacco company marketing strategies. Tob Control. 2002;11(suppl 1):I62-I72.

17. Emery S, White MM, Gilpin EA, Pierce JP. Was there significant tax evasion after the 199950 cent per pack cigarette tax increase in California? Tob Control. 2002;11:130-134.

18. Li Q, Hu T-W, Mao Z, et al. When a tax increase fails as a tobacco control policy: the ITC China project evaluation of the 2009 cigarette tax increase in China. Tob Control. 2012;21:381.

19. Fowkes FJI, Stewart MCW, Fowkes FGR, Amos A, Price JF. Scottish smoke-free legislation and trends in smoking cessation. Addiction. 2008;103:1888-1895.

20. Idris BI, Giskes K, Borrell C, et al. Higher smoking prevalence in urban compared to non-urban areas: time trends in six European countries. Health Place. 2007;13:702-712.

21. Federico B, Mackenbach JP, Eikemo TA, Kunst AE. Impact of the 2005 smoke-free policy in Italy on prevalence, cessation and intensity of smoking in the overall population and by educational group. Addiction. 2012;107:1677-1686.

22. Longo DR, Johnson JC, Kruse RL, Brownson RC, Hewett JE. A prospective investigation of the impact of smoking bans on tobacco cessation and relapse. Tob Control. 2001;10:267-272.

23. Messeri PA, Allen JA, Mowery PD, et al. Do tobacco countermarketing campaigns increase adolescent under-reporting of smoking? Addict Behav. 2007;32:1532-1536.

24. Schaap MM, Kunst AE, Leinsalu M, et al. Effect of nationwide tobacco control policies on smoking cessation in high and low educated groups in 18 European countries. Tob Control. 2008;17:248-255.

25. Martínez-Sánchez JM, Fernández E, Fu M, et al. Smoking behaviour, involuntary smoking, attitudes towards smoke-free legislations, and tobacco control activities in the European Union. PLoS One 2010;5:e13881.

26. Frieden TR, Mostashari F, Kerker BD, Miller N, Hajat A, Frankel M. Adult tobacco use levels after intensive tobacco control measures: New York City, 2002-2003. Am J Public Health. 2005;95:1016-1023.

27. Levy DT, Romano E, Mumford E. The relationship of smoking cessation to sociodemographic characteristics, smoking intensity, and tobacco control policies. Nicotine Tob Res. 2005;7:387-396.

28. Nagelhout GE, Crone MR, van den Putte B, Willemsen MC, Fong GT, de Vries H. Age and educational inequalities in smoking cessation due to three population-level tobacco control interventions: findings from the International Tobacco Control (ITC) Netherlands Survey. Health Educ Res. 2013;28:83-91.

29. Giskes K, Kunst AE, Ariza C, et al. Applying an equity lens to tobacco-control policies and their uptake in six Western-European countries. J Public Health Policy. 2007;28:261-280.

30. Chapman S. Unravelling gossamer with boxing gloves: problems in explaining the decline in smoking. BMJ. 1993;307:429-432. http://www. ncbi.nlm.nih.gov/pmc/articles/PMC1678429/pdf/bmj00034-0039.pdf. Accessed December 30, 2014.

31. Nagelhout GE, van den Putte B, de Vries H, Crone M, Fong GT, Willemsen MC. The influence of newspaper coverage and a media campaign on smokers' support for smoke-free bars and restaurants and on secondhand smoke harm awareness: findings from the International Tobacco Control (ITC) Netherlands Survey. Tob Control. 2012;21:24-29.

32. Levy DT, Chaloupka F, Gitchell J. The effects of tobacco control policies on smoking rates: a tobacco control scorecard. J Public Health Manag Pract. 2004;10:338-353. http://www.lphi.org/LPHIadmin/uploads/TobaccoCont rolPolicies-56291.pdf. Accessed December 30, 2014.

33. Nagelhout GE, Levy DT, Blackman K, Currie L, Clancy L, Willemsen MC. The effect of tobacco control policies on smoking prevalence and smokingattributable deaths. Findings from the Netherlands SimSmoke Tobacco Control Policy Simulation Model. Addiction. 2012;107:407-416. 
34. Hargreaves K, Amos A, Highet G, et al. The social context of change in tobacco consumption following the introduction of "smokefree" England legislation: a qualitative, longitudinal study. Soc Sci Med. 2010;71:459-466.

35. Paul CL, Ross S, Bryant J, Hill W, Bonevski B, Keevy N. The social context of smoking: a qualitative study comparing smokers of high versus low socioeconomic position. BMC Public Health. 2010;10:211.

36. Christakis NA, Fowler JH. The collective dynamics of smoking in a large social network. N Engl J Med. 2008;358:2249-2258.
37. Kotz D, West R. Explaining the social gradient in smoking cessation: it's not in the trying, but in the succeeding. Tob Control. 2009;18:43-46.

38. Hiscock R, Judge K, Bauld L. Social inequalities in quitting smoking: what factors mediate the relationship between socioeconomic position and smoking cessation? J Public Health (Oxf). 2011;33:39-47.

39. Cohen JE, McDonald PW, Selby P. Softening up on the hardening hypothesis. Tob Control. 2012;21:265-266. 